\title{
VINHO: UM PATRIMÔNIO CULTURAL DA HUMANIDADE
}

\author{
Marina Regis Cavicchioli ${ }^{1}$
}

\begin{abstract}
Resumo
Os processos de identificação cultural nos fazem escolher aquilo que queremos como memória, como identidade com o passado, aquilo que queremos preservar. Para tanto, como projetos identitários coletivos elegem-se os patrimônios. As últimas três décadas foram marcadas por um crescente debate em torno da questão da valorização dos diversos tipos de patrimônio cultural. Neste contexto, o vinho, através dos vinhedos e da paisagem que este constrói, das arquiteturas e dos monumentos ligados à ele, bem como suas formas de produção e consumo, coloca-se, através da proteção da UNESCO, como um patrimônio mundial.
\end{abstract}

\section{Palavras-Chave}

Vinho; Identidade; Patrimônio,Política; Paisagem Cultural; UNESCO.

\begin{abstract}
The processes of cultural identification make us choose what we want as memory, what we identity with in the past, and what we want to preserve. This is how we select our cultural heritage projects: as collective identity projects. The last three decades have been marked by a growing debate around the question of valuating the various types of cultural heritage. In this context, wine is considered as a world heritage phenomenon - through the vineyards and the landscape its production creates, the architecture and monuments linked to it, and its forms of production and consumption, through UNESCO's protection.
\end{abstract}

\section{Key words}

Wine; identity; heritage; politics; cultural landscape; UNESCO.

\footnotetext{
1 Professora Doutora, Universidade Federal da Bahia, Salvador, Brasil. E-mail: cavicchioli.marina@gmail.com
} 
Por mais raro que seja, ou mais antigo, só um vinho é deveras excelente: aquele que tu bebes, docemente, com teu mais velho e silencioso amigo

-Mário Quintana

\section{Apresentação: Vinho e identidade}

Quando fui convida para escrever um artigo em homenagem a Pedro Paulo Funari, imediatamente lembrei de todas as discussões teóricas aprendidas com este grande mestre, mas também das muitas taças compartilhadas com este querido amigo e assim, não havia melhor escolha para o objeto deste artigo do que o vinho dentro da perspectiva de patrimônio. Pois, além de todas as justificativas acadêmicas -- as quais serão esmiuçadas mais adiante -- a opção por este tema se deu pelo fato do vinho ser muito especial em nossas vidas, parte intrínseca de nossas identidades: o vinho que me identifica, também o identifica e cria uma identidade comum entre nós, sendo eleito, deste modo, nosso patrimônio cultural comum.

Ele é, em termos freudianos, o objeto revestido de sentidos que nos representa, a parte do eu formado pela identificação melancólica, pelo resto das relações com os outros, sobretudo nossos parentes mais próximos (Freud, 1914: 89-93). O vinho constitui-se assim como traço afetivo velado contido em cada taça, ele retoma o passado distante e tenta torná-lo parte do presente. Deste modo, para ambos, descendentes de famílias de imigrantes italianos, o vinho é um importante coadjuvante no jogo de relações identitárias entre a famiglia e a "pátria abandonada". Stuart Hall evidencia como a diáspora -e aqui incluo também a imigração - interfere sobremaneira nos processos de identidade cultural (Hall, 2003: 28).

Os processos de identificação cultural nos fazem, ainda, eleger aquilo que queremos como memória, como identidade com o passado ou ainda aquilo que queremos preservar.

Assim, como projetos identitários coletivos elegem-se os patrimônios, conforme bem nos aponta Funari: 
(...) A eleição destes patrimônios, dentro da vertente teórica pós-moderna, é compreendida como escolha política, voltada à construção de determinados projetos identitários. Esta possibilidade de leitura do patrimônio é apoiada na própria historicidade do conceito. As línguas românicas usam termos derivadas do latim patrimonium para se referir à 'propriedade herdada do pai ou dos antepassados, uma herança'. Os alemães usam Denkmalpflege, 'o cuidado dos monumentos, daquilo que nos faz pensar', enquanto o inglês adotou heritage, na origem restrito 'àquilo que foi ou pode ser herdado' mas que, pelo mesmo processo de generalização que afetou as línguas românicas e seu uso dos derivados de patrimonium, também passou a ser usado como uma referência aos monumentos herdados das gerações anteriores. Em todas estas expressões, há sempre uma referência à lembrança, moneo (em latim, 'levar a pensar', presente tanto em patrimonium como em monumentum), Denkmal (em alemão, denken significa 'pensar') e aos antepassados implícitos na 'herança' (...)" (Funari e Pelegrini, 2006: 10-13).

\section{A Unesco e o reconhecimento das culturas e dos patrmônios.}

Se os estados nacionais se utilizaram da ideia de um patrimônio coletivo homogêneo, comum a toda a população, pautado sobretudo nos monumentos, para a legitimação de uma identidade nacional, (Cagneta, 1979; Carandini, 1995; Zevi, 2001), o período pós Segunda Guerra Mundial abriu-se para as diferenças e valorização das diversidades.

As conferências sobre a paz realizadas no final da segunda guerra e o medo ao retorno dos estados nacionalistas imperialista, levaram a criação da Organização das Nações Unidas (ONU) em fevereiro de 1945 (Nações Unidas, 2017). ${ }^{2}$ Naquele mesmo ano, em novembro, foi criada A Organização das Nações Unidas para a Educação, a Ciência e a Cultura UNESCO - "com o objetivo de garantir a paz por meio da cooperação intelectual entre as nações, acompanhando o desenvolvimento mundial e auxiliando os Estados-Membros...na busca de soluções para os problemas que desafiam nossas sociedades." (UNESCO, 2017). ${ }^{3}$

A UNESCO criou uma série de ações para a troca de conhecimento científico e intelectual contando com a padronização de diplomas e

\footnotetext{
2 Inicialmente a Carta das Nações Unidas foi assinada por 50 países, excluindo aqueles que haviam feito parte do Eixo, que só entrariam para a organização algum tempo depois.

${ }^{3}$ Os primeiros acordos da UNESCO iniciaram-se em dezembro de 1948.
} 
investimentos em educação. Numa tentativa de maior tolerância entre as diferentes nações e a valorização da cultura dos diferentes países e seu respectivo povo, bem como de especificidades dos territórios, a UNESCO realizou também conferências das quais se seguiram recomendações, declarações e a adoção de algumas convenções aprovadas mundialmente para a valorização e proteção ao patrimônio cultural e natural:4

Quando, apesar das diferenças culturais e das tradições, os Estados concordam com regras comuns, podem elaborar um instrumento internacional: um acordo ou convenção, que são juridicamente vinculativos, uma recomendação ou uma declaração... A UNESCO participa neste esforço através da sua ação normativa, servindo como um fórum central para coordenar as questões éticas, normativas e intelectuais do nosso tempo, promovendo o intercâmbio multidisciplinar e o entendimento mútuo, trabalhando - quando possível e desejável - para acordos universais sobre essas questões, definindo pontos de referência e mobilizando a opinião internacional." (UNESCO, 2017. Tradução da autora)

Contudo, é importante notar que o conceito de patrimônio inicialmente utilizado pela UNESCO vinculava-se à ideia de monumento, objeto de arte e identidade nacional, vistos de maneira homogênea e uniforme. Por outro lado, podemos assistir a uma mudança significativa de paradigmas no decorrer das décadas, como apresentaremos a seguir.

\section{A Proteção dos Bens Culturais}

Ainda muito influenciada pelos conflitos da Segunda Guerra Mundial, a UNESCO promulgou A Convenção para a Proteção dos Bens Culturais em Caso de Conflito Armado, também conhecida como Convenção de Haia de 1954, que teve um segundo protocolo adicionado em 1999. Em seu artigo primeiro temos a definição de propriedade cultural adotada então:

$(\ldots)$

Disposições gerais respeitantes a proteção:

Artigo $1^{\circ}$

- Definição de bens culturais

Para fins da presente Convenção, são considerados como bens culturais, qualquer que seja a sua origem ou o seu proprietário:

\footnotetext{
${ }^{4}$ As convenções internacionais estão sujeitas a ratificação, devendo ser aceitas pelos Estados uma vez que elas definem regras que os estados devem cumprir.
} 
a) Os bens, móveis ou imóveis, que apresentem uma grande importância para o patrimônio cultural dos povos, tais como os monumentos de arquitetura, de arte ou de História, religiosos ou laicos, ou sítios arqueológicos, os conjuntos de construções que apresentem um interesse Histórico ou Artístico, as obras de arte, os manuscritos, livros e outros objetos de interesse artístico, Histórico ou arqueológico, assim como as coleções científicas e as importantes coleções de livros, de arquivos ou de reprodução dos bens acima definidos;

b) Os edifícios cujo objectivo principal e efetivo seja, de conservar ou de expor os bens culturais móveis definidos na alínea a), como são os museus, as grandes bibliotecas, os depositórios de arquivos e ainda os refúgios destinados a abrigar os bens culturais móveis definidos na alínea a) em caso de con-

flito armado;

c) Os centros que compreendam um número considerável de bens culturais que são definidos nas alineas a) e b), os chamados "centros monumentais»." (DIARIO DA REPUBLICA - I SERIE-A N.o 76 - 30 de Março de 2000).

Em seguida podemos destacar A Recomendação de Nova Delhi de 1956 que centrava-se na proteção ao patrimônio arqueológico e museológico. Já a recomendação de Paris de 1962 incluiu a proteção da beleza e das paisagens, bem como seus respectivos territórios. Deste modo, podemos perceber uma ampliação do conceito de patrimônio cultural, estendido à beleza e as paisagens de sítios naturais, rurais ou urbanos. ${ }^{5}$ Em 1964 a preocupação foi outra: a Recomendação Paris de 1964 discorre sobre medidas para proibir e impedir a exportação, a importação, bem como a transferência de propriedade ilícita de bens culturais.

Em 1966 houve a Declaração dos Princípios da Cooperação Cultural Internacional. Nela percebemos, em seu artigo primeiro, as tentativas de valorização das diferentes culturas:

ARTIGO 1. ${ }^{\circ}$

1. Toda a cultura tem uma dignidade e um valor que devem ser respeitados e salvaguardados.

2. Todos os povos têm o direito e o dever de desenvolver as respectivas culturas.

3. Todas as culturas fazem parte do patrimônio comum da humanidade, na sua variedade fecunda, diversidade e influência recíproca." (UNESCO, 2017)

Uma temática diferente foi abordada na Recomendação Paris de 1968 que preocupou-se com os problemas gerados pelo crescimento urbano, com

\footnotetext{
${ }^{5}$ Neste mesmo ano foi elabora a Carta de Veneza, outra carta patrimonial, mas desta vez criada pelo ICOMOS, demonstrando que os debates em torno do patrimônio estavam ocorrendo em diversos espaços.
} 
recomendações sobre as intervenções urbanas (públicas e privadas ) relacionadas com o patrimônio.

Em 1971 foi a vez da Convenção sobre as Zonas Úmidas de Importância Internacional, especialmente enquanto habitat de aves aquáticas. O Meio Ambiente voltou a ser ponto de pauta na Convenção de Estocolmo sobre o Meio Ambiente Humano, cujo resultado foi a Declaração de Estocolmo de 1972 que buscou estabelecer critérios comuns para preservação e melhoria do meio ambiente.

Provavelmente uma das mais conhecidas Convenções da UNESCO foi a Recomendação de Paris sobre a Proteção do Patrimônio Mundial, Cultural e Natural, de 1972.

Nesta Convenção foi proposto um programa de proteção nacional e internacional de bens por meio da promoção da consciência de preservação para as gerações presentes e futuras (IPHAN Recomendação Paris, 1972). Assinada pelos 159 estados participantes, constituiu-se uma ferramenta que reconhece -a partir de seus próprios critérios e parâmetros- e protege o patrimônio cultural e natural de valor mundial. A UNESCO tornou-se, assim, um dos mais importantes órgãos mundiais como referência ao reconhecimento e proteção aos patrimônios. ${ }^{6}$

Em 1976 temos as Recomendações de Nairóbi cujo tema central foi a salvaguarda dos conjuntos históricos e sua função na vida contemporânea. Mas foi na Recomendação Paris de 1989 que percebemos uma ampliação no conceito de cultura com a Recomendação sobre a Salvaguarda da Cultura Tradicional e Popular (IPHAN - Recomendação Paris, 1989).

(...) a Recomendação de Paris (1989) atribui à cultura um importante papel social, econômico e político, reconhecendo o valor da identidade nacional. Destaca a importância da difusão dos conhecimentos patrimoniais para o bem comum da sociedade e a criação de mecanismos para a proteção dessa cultura, tendo a educação como foco principal neste processo. (Campos, Rodrigues e Funari, 2017: 336)

\footnotetext{
6 Embora a UNESCO seja uma organização mundial de reconhecimento ímpar, é importante destacar que as discussões internacionais para proteção e a valorização do Patrimônio já vinham ocorrendo anteriormente, como nos fazem ver as Cartas de Atenas de 1931 e 1933.
} 
A Carta do Rio de 1992 é uma volta a questão do meio Ambiente e Desenvolvimento. Ela reafirma a Declaração aprovada em Estocolmo, de 1972, e apresenta 28 princípios a fim de estabelecer nova aliança e novos níveis de cooperação para alcançar os acordos internacionais que visam a integridade do sistema ambiental e do desenvolvimento mundial (IPHAN - Carta do Rio, 1992).

Neste mesmo ano houve a inclusão da categoria de paisagem cultural dentro do Patrimônio Cultural da Humanidade. A Convenção de 1992, em seu artigo 1o. definiu que as paisagens culturais representam as “obras conjugadas do homem e da natureza". (UNESCO, 2017).

Em 1997 a UNESCO criou a chancela do Patrimônio Oral e Imaterial da Humanidade e, em 2003, houve a Convenção para a Salvaguarda do Patrimônio Cultural Imaterial. Em 2001 foi a vez da Proteção do Patrimônio Cultural Subaquático. Já em 2005 houve a aprovação, com ampla maioria da Convenção sobre Proteção e Promoção da diversidade de expressões culturais.

Digno de nota é a convenção da UNESCO de 2005, que trata da proteção e promoção da diversidade e das expressões culturais. Ela reconhece, ao longo da última década, o direito soberano dos governos de introduzir políticas para proteger e promover a diversidade de expressões culturais. Enfatiza que a dimensão econômica está intrinsicamente ligada à dimensão cultural gerando empregos e renda, fomentando a inovação e o crescimento econômico sustentável e, ao mesmo tempo, transmitindo identidades e valores, promovendo a inclusão social e o senso de pertencimento (Bokova, 2016 In Campos, Rodrigues e Funari, 2017: 330).

No tocante a questão cultural, na atualidade, a Unesco reconhece a CULTURA como:

Fundamento da identidade, da energia e das ideias criativas dos povos, a cultura, em toda sua diversidade, é fator de desenvolvimento e coexistência em todo o mundo. Nesse sentido, a UNESCO elabora e promove a aplicação de instrumentos normativos no âmbito cultural, além de desenvolver atividades para a salvaguarda do patrimônio cultural, a proteção e o estímulo à diversidade cultural, bem como o fomento ao pluralismo e ao diálogo entre as culturas e civilizações. (UNESCO, 2017) 


\section{Reconhecendo um patrimônio}

As últimas três décadas, como vimos, foram marcadas por um crescente debate em torno da questão da valorização dos diversos tipos de patrimônio cultural, que envolveu, além da UNESCO, órgãos públicos como prefeituras, Secretarias de Cultura de Governos, e outros órgãos internacionais, ${ }^{7}$ como o caso do ICOMOS$^{8}$ e o meio acadêmico. Esses debates influenciaram de maneira decisiva a reformulação do conceito de patrimônio de forma que, além dos tradicionais monumentos, novos elementos tanto materiais como imateriais, ganharam o status de patrimônio.

Assim, a partir das muitas convenções, percebemos que novos objetos, materiais e imateriais, foram sendo incorporados de forma que construções, artefatos, paisagens, canções, fábulas, alimentos, modos de fazer, passaram a designar patrimônios culturais. Todavia, devemos ressaltar que nenhuma destas coisas é a priori um patrimônio. Este é resultado de uma escolha arbitraria caracterizada por uma intenção política: um objeto torna-se patrimônio porque um grupo de pessoas decide investi-lo de um valor especial (Chastel, 1997:,143).

Pois é na medida em que um objeto opera como símbolo comum a um específico grupo de indivíduos, tornando-se representante de sua cultura e revestido de importância a ponto de forjar sua identidade, é que ele pode tornar-se um patrimônio. Sabemos também que estes símbolos ganham ainda mais apreço quando são vinculados a uma longa tradição e a História, considerada como um passado coletivo, também é um elemento chave legitimador de identidades.

Foi neste sentido que o vinho, englobando desde o própria bebida até os modos de seu preparo e consumo, pois estes são reveladores de relações sociais, econômicas e, sobretudo culturais, ganhou status de patrimônio. Deste modo, o vinho passou a ocupar um espaço bastante especial no rol do patrimônio cultural. Um dos exemplos que podemos citar foi a criação em 2006 foi da Cátedra UNESCO Cultura e Tradições do Vinho. Sediada na Universidade de Borgonha englobando o Instituto Jules Guyot e a

\footnotetext{
7 Cabe-nos ressaltar, que além das cartas patrimoniais geradas pelas convenção da UNESCO, outras instituições,elaboraram importantes cartas preocupados com a salvaguarda dos bens culturais de diversas naturezas.

8 Conselho Internacional de Monumentos e Sítios.
} 
Maison des Sciences de l'Homme de Dijon, mas incorporando participantes de diversos países dos cinco continentes, tem em sua justificativa a ideia do vinho como um produto cultural, um patrimônio a ser salvaguardado:

Todas as atividades da Cátedra são focadas em uma abordagem multidisciplinar e internacional do vinho como produto "cultural" por excelência. Ela se inscreve nos programas prioritários da UNESCO, tais como a divulgação de educação e da pesquisa... e a salvaguarda do patrimônio. Como tal, todas as disciplinas, tanto as ciências exatas, como as ciências humanas e sociais, estão envolvidas na problematica das vinhas, do vinho e do seu património cultural (Chaire Unesco Vin et Culture, 2006. Tradução da Autora)

A criação desta cátedra não foi um fenômeno isolado. No ano de 2006, em decorrência da aprovação no ano anterior da Convenção sobre Proteção e Promoção da Diversidade de Expressões, eventos internacionais sobre patrimônio debateram a entrada do terroir na lista dos Patrimônios Culturais da Humanidade (Cavicchioli, 2006: 73).

O conceito de terroir se mostra amplo e polêmico e não foi institucionalizado pelo UNESCO. Contudo, esta instituição que desde 1992 incorporou o conceito de Paisagem Cultural, o que possibilitou a inclusão das paisagens vinícolas nesta categoria, bem como, alguns modos de produção desta bebida no patrimônio cultural imaterial, como trataremos a seguir.

\section{A Paisagem Cultural: a Construção de Um conceito}

O que são paisagens? Há, já, uma particularidade linguística nessa questão. $O$ Conselho Internacional de Museus (ICOM), ao apresentar o tema 'Museus e paisagens culturais', introduziu uma diversidade de conceitos. Em inglês, há uma ênfase particular na terra (land), por oposição a outros termos que existem nesse idioma e que se referem ao ambiente urbano (cityscape) e até mesmo vista do céu (skyscape). Já nos idiomas neolatinos do ICOM, em francês e espanhol, a expressão paisagem (paysage, paisage) deriva de país, termo que designa a terra e precisa de adjetivos para designar a paisagem urbana ou do céu. Isto significa que a paisagem cultural define-se pela relação entre o ser humano e a natureza, pois a terra (land) e o país são criações humanas. Neste âmbito, paisagem cultural apenas intensifica, com o adjetivo, o aspecto humano do contexto natural. Paisagens, portanto, são uma mescla daquilo que cresce e frutifica (este o sentido de physis, em grego, e de natura, em latim, aquilo que 
nasce e cresce) e de como os humanos interpretam, manipulam e transformam o ambiente. Paisagem cultural, com esses dois termos, coloca a ênfase nessa apropriação humana. Assim, tanto museus como paisagens culturais estão centradas no ser humano, cujas características são as mais contraditórias (Funari, 2016).

Inicialmente a Convenção sobre a Proteção do Patrimônio Mundial, Cultural e Natural de 1972 distinguia os patrimônios naturais e culturais, cuja avaliação e julgamento eram realizados por grupos distintos de especialistas. Os patrimônios culturais eram divididos alocados em três grandes categorias: monumentos, conjuntos e sítios. Já os naturais, em outras três: monumentos naturais, formações geológicas e fisiográficas e sítios naturais. Havia ainda os sítios considerados mistos que deveriam atender tanto aos critérios e categorias dos patrimônios naturais quanto culturais. (UNESCO, 2009: 16).

Com a Convenção de 1992 e a inclusão da categoria de Paisagem Cultural dentro do Patrimônio Cultural da Humanidade, embora os sítios de categorias mistas pudessem continuar a ser inscritos, este categoria ganhou grande destaque e uma enorme ênfase foi dada na interação homem/paisagem natural, sendo a cultura o agente. Para a UNESCO:

O termo "paisagem cultural" abrange uma diversidade de manifestações da interação entre a humanidade e seu ambiente natural. As paisagens culturais muitas vezes refletem técnicas específicas de uso sustentável da terra, considerando as características e os limites do ambiente natural em que estão estabelecidos e uma relação espiritual específica com a natureza. A proteção das paisagens culturais pode contribuir para técnicas modernas de uso sustentável da terra e pode manter ou melhorar os valores naturais na paisagem. A existência contínua de formas tradicionais de uso da terra possibilita a diversidade biológica em muitas regiões do mundo. A proteção das paisagens culturais tradicionais é, portanto, útil na manutenção da diversidade biológica. (UNESCO, 2017. Tradução da autora)

Assim, a UNESCO considera ainda que:

...existe uma grande variedade de paisagens que são representativas das diferentes regiões do mundo. Obras combinadas da natureza e do homem, elas expressam uma longa e intima relação...As paisagens Culturais são ilustrativas da evolução da sociedade humana e a sua consolidação ao longo do tempo, sob a influência das condicionantes físicas e/ou das oportunidades apresentadas pelo seu ambiente natural e das sucessivas forças sociais, econômicas e culturais, externas e internas. (UNESCO, 2008: 22-23. Tradução da autora). 


\section{O Vinho como Patrimônio}

Dentro da categoria de paisagens culturais algumas regiões produtoras de vinho receberam a chancela de patrimônio mundial pela UNESCO.

A primeira delas foi a Jurisdição de Saint-Emilion, na região de Bordeaux, no sudoeste francês, em 1999. Uma das regiões produtoras de vinhos de alta qualidade mais reconhecidas do mundo, a região é repleta de chateaux históricos como o Château Cheval Blanc (que também recebeu no mesmo ano a chancela de patrimônio da humanidade) e é produtor de icônico vinho de mesmo nome.

Além dos chateaux existe uma série de monumentos históricos medievais, como vemos na própria cidade de Saint-Emilion, fundada no 8o. século e que ainda conserva construções medievais. Contudo os critérios para a entrada da Jurisdição de Saint-Emilion não foi a qualidade de seus vinhos, e nem mesmo o conjunto de seus chateaux, ou os resquícios da cidade medieval, como construções isoladas, foram também seus vinhedos históricos que formam a impressionante paisagem, onde os monumentos são coadjuvantes: “A grande particularidade desta região que a torna um sitio único é de ter conservado as estruturas agrárias de outros séculos, como as da idade média." (UNESCO, 2005: 21).

Para entrar na lista de Patrimônios Mundial o sítio deve ter um valor universal excepcional e atender a pelo menos um critério de seleção utilizado pela Unesco. É importante lembrar que até o fim de 2004 os sites do Patrimônio Mundial foram selecionados com base em seis critérios culturais e quatro naturais. Com a adoção das Diretrizes Operacionais revisadas para a Implementação da Convenção do Patrimônio Mundial, existe apenas um conjunto de dez critérios. Dentre eles, as paisagens vitivinícolas respondem geralmente a um dos seguintes critérios:

(ii) - exibir um importante intercâmbio de valores humanos, ao longo de um período de tempo ou dentro de uma área cultural do mundo, sobre desenvolvimentos em arquitetura ou tecnologia, artes monumentais, urbanismo ou paisagem;

(iii) - ter um testemunho único ou pelo menos excepcional de uma tradição cultural ou de uma civilização viva ou que tenha desaparecido;

(iv) - ser um excelente exemplo de um tipo de conjunto arquitetônico ou tecnológico ou paisagem que ilustra estágio(s) significativo(s) na história humana; 
(iv) - ser um excelente exemplo de um assentamento humano tradicional, uso da terra ou uso do mar que é representativo de uma cultura (ou culturas), ou interação humana com o meio ambiente, especialmente quando se tornou vulnerável sob o impacto de mudanças irreversíveis; ser um excelente exemplo de um assentamento humano tradicional, uso da terra ou uso do mar que é representativo de uma cultura (ou culturas), ou interação humana com o meio ambiente, especialmente quando se tornou vulnerável sob o impacto de mudanças irreversíveis;

Assim, Saint-Emilion, responde aos critérios iii e v da seguinte modo:

Critério (iii): A jurisdição de Saint-Emilion é um excelente exemplo de uma paisagem de vinha histórica que sobreviveu intacta e em atividade até o presente.

Critério (iv): o cultivo intensivo de uvas para a produção de vinho em uma região precisamente definida e a paisagem resultante é ilustrada de forma excepcional pela jurisdição histórica de Saint-Emilion.

Após a inclusão de Saint-Emilion, a porta estava aberta para a entrada de outras paisagens culturais com cultivo de videiras na lista dos patrimônios mundiais.

Atualmente fazem parte da lista : Wachau, na Áustria; a região do Alto Douro em Portugal; a região de Fertö/Neusiedlersee situada na fronteira entre a Hungria e a Áustria; O Vale do Médio Alto Reno na Alemanha; a região de Tocaj na Hungria; a Ilha do Pico em Portugal; Lavaux na Suiça;o Piemonte na Itália; Champagne e a Borgonha na França.

\section{Paisagens Vinícolas e Identidade Cultural}

Embora seja possível considerar que as paisagens culturais acima citadas valorizem um patrimônio sobretudo europeu, devemos reforçar que estas escolhas não são apenas o reflexo das políticas da UNESCO, mas também das candidaturas que referem-se a ações políticas e identitárias nacionais ou regionais. Neste sentido, algumas questões devem ser consideradas.

O vinho, embora tenha sido a primeira bebida a ter entrado, ainda que de forma indireta, na lista dos patrimônios mundial da UNESCO, não é um caso isolado: também a Tequila mexicana foi incorporada como patrimônio, uma vez que as paisagens culturais com a cultura tradicional do agave também são patrimônio Mundial da UNESCO. 
Outro caso relevante é o da Paisagem Cultural do Sul de Jerusalém, Battir. Denominada como : "Palestina: Terra das Oliveiras e VideirasPaisagem Cultural do Sul de Jerusalém, Battir. (Palestine: Land of Olives and Vines - Cultural Landscape of Southern Jerusalem, Battir) ela entrou para a lista da UNESCO em 2014. Embora grande ênfase seja dada a produção de uvas, existente desde a Antiguidade, nenhuma menção é feita a produção de vinhos. Sabemos que a região foi produtora da bebida durante muitos séculos na antiguidade, mas, por questões religiosas e culturais na atualidade, não há a intenção de estabelecer um vínculo com este passado produtor de vinho de forma a torna-lo um patrimônio.

O patrimônio é uma forma de construir uma memória coletiva, pois, é em grande medida, reflexo de uma cultura, revelando um grupo que se identifica com ele, ele é ao mesmo tempo construtor e legitimador de identidades nacionais, regionais, étnicas, religiosas e de gênero. Neste sentido, o patrimônio é o conjunto de relações sociais que o envolvem. Assim, "O que para uns é patrimônio para outros não é...Além disso, os valores sociais mudam com o tempo" (Funari e Pelegrini, 2006: 10).

Quais seriam então as razões para que uma determinada região produtora de vinho tente se inscrever na lista dos patrimônios mundiais da UNESCO? Uma das possibilidades é o alto grau de envolvimento turístico e a consequente ganho econômico que isto poderia gerar:

A chancela da UNESCO dá aos sítios um emblema de Patrimônio Mundial que constitui um atrativo cultural e econômico, tanto para as regiões e países em que os sítios se localizam como para o importante fluxo de turismo cultural e ecológico. O turismo cultural é um dos principais subprodutos da classificação de um sítio como patrimônio da humanidade (Funari e Pelegrini, 2006: 26).

Sabemos também que em muitos países este é um fator importante para incentivar os governos a investirem verbas públicas na preservação, pesquisa e divulgação de conhecimento sobre determinados sítios. Contudo, cabe ressaltar que um estudo realizado pela PricewaterhouseCoopers, em 2007, sobre os custos e benefícios de um sítio estar na lista da UNESCO, demonstra o alto custo para uma demanda de concorrer a Patrimônio Mundial da humanidade da UNESCO (PricewaterhouseCoopers, 2007:2-4 e 11-13). 
Da mesma maneira, é importante ressaltar, como vimos anteriormente, o papel das identidades: grupos se apoiam na lista da UNESCO na busca de uma legitimação e valorização mundial de sua tradição cultural e paisagística, produtora e consumidora de vinhos, buscando preservá-la: orgulho e identidade são ainda fatores relevantes na escolha do patrimônios.

Entretanto, se o vinho é um elemento de identidade para aqueles que vivem em regiões produtoras e seus descentes, como e porque ele se tornou um patrimônio mundial da humanidade? De acordo com a UNESCO, o patrimônio Mundial da Humanidade é aquele digno não apenas de uma região, mas de toda a humanidade.

Para entrar na célebre lista, é necessário provar que estas paisagens culturais são parte de um cenário de valor universal excepcional e que a produção vinícola é um fator determinante na paisagem

natural e no contexto cultural e histórico do local.

A ideia de que o patrimônio de uma região pode tornar-se universal vem das bases da Unesco no contexto do pós Segunda Guerra Mundial. Baseados em um ideal de diversidade humana e ambiental como valor universal a ser promovido. (Funari e Pelegrini, 2006:23).

\section{Conclusões}

A preservação das paisagens culturais e dos modos tradicionais da produção do vinho, bem como a divulgação e o acesso das pesquisas a um público amplo, são elementos essenciais para a valorização do patrimônio cultural do vinho. Pois, na medida em que as pessoas o conhecem, podem identificar-se com ele, compreendendo ser de interesse público a sua preservação.

Embora isto ocorra tradicionalmente por relacionar este patrimônio com uma herança cultural própria de um grupo que preserva determinadas origens, atualmente, essa identificação também vem sendo incorporada por alguns grupos em virtude da empatia consequente da paixão por esta bebida, que conduz, muitas vezes, a uma busca de novos conhecimentos sobre a cultura que a cerca. 
Deste modo, ainda que materialmente nem todos possam ter acesso as garrafas de um Cheval Blanc, de um Tokaji, um Barolo, entre tantos outros, o vinho torna-se, ao menos do ponto de vista da cultural, um patrimônio da humanidade.

O vinho, através dos vinhedos e da paisagem que este constrói, das arquiteturas e dos monumentos ligados à ele, bem como suas formas de produção e consumo, coloca-se, através da proteção da UNESCO como um patrimônio mundial.

Em vista disso, apesar das ressalvas que podem ser feitas considerando este patrimônio (com suas paisagens) como um patrimônio sobretudo europeu, sua aceitação e aprovação por uma assembleia composta também por membros de países onde o álcool é proibido e não aceito por questões religiosas, pode ser vista como tolerância a diversidade.

Se por um lado a aprovação deste patrimônio vincula-se à questões políticas e econômicas importantes, por outro vincula-se as questões identitárias e de empatia em relação a bebida. Portanto, se a escolha do vinho como patrimônio pode partir de uma relação muitas vezes afetiva, esta dimensão é importante nas relações sociais e políticas, considerando que há uma adesão social construída através das afecções (Safatle, 2016: 17). Assim, o orgulho identitários de alguns pode se refletir em lucro para outros, mas o mundo todo pode brindar à proteção deste patrimônio!

\section{Bibliografia}

BOKOVA, I. Prefácio: re/pensar as políticas culturais: 10 anos de promoção da diversidade das expressões culturais para o desenvolvimento. Paris: Unesco, 2016. (Relatório Global da Conven- ção 2015).

em: <http://unesdoc.unesco.org/images/0024/002430/ 243029por.pdf>. Acesso em: 20 nov.2016.

CAGNETTA, Marinella: Antichisti e impero fascista. Bari: Dedalo Libri, 1979.

CARANDINI, Andrea: Archeologia e Cultura Materiale. Roma: De Donato, 1995. 
CAMPOS, Juliano; RODRIGUES, Mirian Helen e FUNARI, Pedro Paulo Abreu. O Patrimônio Arqueológico no Licenciamento Cultural: Legislação, Políticas Culturais e Gestão Integrada. In Oculum ensaios. N14 (2)Dossiê Patrimônio Arqueológico. Campinas : Maio-Agosto 2017, p.331-347.

CAVICCHIOLI, Marina. O terroir e a Identidade Cultural. In Adega. Ano 6, no10, 2006.

CHAIRE UNESCO VIN et CULTURE. https://chaireunescovinetculture.u-bourgogne.fr. Acesso em: 26 de agosto de 2006.

CHASTEL, Andre: La notion de patrimoine, in Pierre. Nora (ed.), Les lieux de mémoire (1984-1992). Paris: Gallimard, 1997, p. 1433-1469

FREUD, Sigmund. (1914). Narcisismo: uma introdução. In: A história do movimento psicanalítico, artigos sobre metapsicologia e outros trabalhos. Rio de Janeiro: Imago, 1976. p. 85-120 (Edição standard brasileira das obras psicológicas completas de Sigmund Freud, XIV).

FUNARI, Pedro Paulo Abreu; ORSER JÚNIOR, Charles; SCHIAVETTO, Solange: Identidades, discurso e poder: Estudos da arqueologia contemporânea. São Paulo: Annablume, 2005.

FUNARI, Pedro Paulo Abreu e PELEGRINI, Sandra Cássia. Patrimônio Histórico e Cultural. Rio de Janeiro: Jorge Zahar Editor: 2006.

FUNARI, Pedro Paulo Abreu. Museus e paisagens culturais: avanços e desafios. .In Revista Museu.com.br, 2016,249. Disponível em : http://www.revistamuseu.com.br/site/index.php/br/artigos/18-demaio/249-

IPHAN. Instituto do Patrimônio Histórico e Artístico Nacional (Brasil). Cartas patrimoniais. 3 ed. rev. e aum. Rio de Janeiro: IPHAN, 2004.

ONU. Disponível em: < https://nacoesunidas.org acesso em 16 de outubro de 2017.

PricewaterhouseCoopers, (PWC): 'The Costs and Benefits of UK World Heritage Site Status, A literature review for the Department for Culture, Media and Sport do Reino Unido, 2007. 
PORTUGAL: Diário Da República - Resolução da Assembleia da República n.o 26/2000 que Aprova, para ratificação, a Convenção para a Proteç̧ão dos Bens Culturais em Caso de Conflito Armado, adotada na Haia em 14 de Maio de 1954. - I SERIE-A N.o 76 - 30 de Março de 2000.

SAFALTE, Vladimir. Circulo do Afetos: Corpos políticos, desamparo, e o fim do indivíduo. São Paulo: Autêntica Editora, 2016.

RECOMENDAÇÃO de Nova Delhi, 1956. Disponível em: <http:// portal.iphan.gov.br/uploads/ckfinder/arquivos/Recomendaca o\%20de\%20Nova\%20Dheli\%201956.pdf.

UNESCO, Cultural Landiscape. Disponível em:,<http://whc.unesco.org/en/culturallandscape> .Acessos em novembro de 2017

UNESCO. The World Heritage List. Disponível: em <http://whc.unesco.org/en/list>. Vários acessos em: de setembro a novembro de 2017.

UNESCO; World Heritage Committee (WHC). Operational guidelines for the implementation of the world heritage convention. Paris: UNESCO, 2008. Disponível em: <http://whc.unesco.org/archive/opguide08-pt. pdf>. Acesso em: 28 ago. 2017.

\section{UNESCO.}

www.unesdoc.unesco.org/images/0012/001271/127160por.pdf. Vários acessos em setembro e outubro de 2017.

ZEVI, Fausto. Aspetti dell archeologia pompeiana nel Novecento: gli scavi Del Mauri a Pompei. In GUZZO, Pier Giovanni (org.). Pompei Scienza e Societá. Milão: Electa, 2001. 